\title{
Clinical and Bacteriological Profile of UTI Patients in Medicine Department in a Teaching Hospital of Bangladesh
}

\author{
F AHMED ${ }^{\mathrm{a}}$, ME HOSSAIN ${ }^{\mathrm{b}}, \mathrm{MG} \operatorname{HOSSAIN}^{\mathrm{c}}$, G KARMAKER ${ }^{\mathrm{d}}$, MR KABIR ${ }^{\mathrm{e}}$, IA CHOWDHURY ${ }^{\mathrm{f}}$, MC PAUL $^{\mathrm{g}}$, HS PAL $^{\mathrm{h}}$
}

\begin{abstract}
:
Introduction: Urinary tract infections (UTIs) encompass a wide array of infections, accounting for a vast number of community as well as hospital acquired infections. This study was undertaken to evaluate the clinical presentations and bacteriological profile of UTI patients in indoor setting.
\end{abstract}

Methods: This 6 months cross-sectional study enrolled 100 patients admitted in Medicine department of Sylhet MAG Osmani Medical College Hospital with symptoms and signs of UTI subsequently confirmed by compatible investigations including urine culture.

Results: Among 100 patients of UTI, maximum were females (67\%) and the male female ratio was 0.49: 1. The most common age group was 46-60 years (34\%). Majority (68\%) of the patients had upper UTI while lower UTI constitutes $32 \% .66 \%$ of the patients had complicated while $34 \%$ have

Introduction:

Urinary tract infection (UTI) may be defined as inflammatory disorders of the urinary tract caused by abnormal growth of pathogens ${ }^{1}$. UTI is one of the

a. Dr. Ferdaus Ahmmed, Concepts, Design, Literature Search, Manuscript review

b. Dr. Md. Enayet Hossain, Concepts, Design, Literature Search, Manuscript review

c. Dr. Md. Guljar Hossain, Data Analysis, Literature Search, Manuscript review

d. Dr. Gobinda Karmaker, Concepts, Manuscript editing, Manuscript review

e. Mohammed Ruhul Kabir, Data Analysis, Manuscript review

f. Iqbal Ahmed Chowdhury, Manuscript editing, Manuscript review

g. Dr. Mukul Chandra Paul, Data Analysis, Manuscript review

h. Dr. Hitangshu Shekhar Pal, Data Analysis, Manuscript review

Adddress of Correspondence: Dr. Ferdaus Ahammed, Assistant Professor, Dept. of Medicine, Sylhet MAG Osmani Medical College, 113/1, 2nd Floor, Kajalshsah, Sylhet 3100. Cell: 01717518609, E-mail: ferdauscom7@gmail.com

Received: 29 September, 2020

Accepted: 15 February, 2021 uncomplicated UTI.18\% of the patients had recurrent UTI. Most of the patients had fever (55\%), followed by loin pain (37\%) as their presenting symptoms. The most common risk factor was loss of host defense 38\% (diabetes mellitus/ use of immunosuppressive drugs). Out of 100, 60 urine samples were positive for pathogenic organisms. Escherichia coli was isolated in 41 (68.3\%) of the positive samples, followed by Klebsiella sp 13 (21.6\%), Pseudomonas sp 3 (5\%) Proteus sp 2 (3.3\%) Staph. Aureus 1(1.66\%).

Conclusion: The most common clinical presentations of UTI in admitted UTI patients are fever and loin pain. Diabetes mellitus is the most important risk factor. Mainly Gram negative bacilli were found to be responsible for UTI and most frequent isolated bacteria was E-coli.

(J Bangladesh Coll Phys Surg 2021; 39: 106-113)

DOI: https://doi.org/10.3329/jbcps.v39i2.52391

most common bacterial infections among male and female affecting 150 million people worldwide ${ }^{2,3}$. In Bangladesh it is also one of the most important causes of morbidity at both outdoor and indoor setting. Lack of proper research, faulty diagnostic procedures, abuse of chemotherapeutic agents and little or no preventive measures are all common attributing factors ${ }^{4}$.

Clinically, UTI is uncomplicated and complicated. When the infection occurs in otherwise healthy and has no structural or neurological urinary tract abnormalities, it is an uncomplicated $\mathrm{UTI}^{5}$. Complicated UTIs are defined as UTIs associated with factors that compromise the urinary tract or host defense, including urinary obstruction, urinary retention caused by neurological disease, immunosuppression, renal failure, renal transplantation, pregnancy, and the presence of foreign bodies such as calculi, indwelling catheters, or other drainage devices ${ }^{6,7}$. 
It is reported that $70-80 \%$ of complicated UTIs are attributable to indwelling catheters, accounting for 1 million cases per year in the United States ${ }^{8}$. Risk factors for developing a catheter associated UTI include prolonged catheterization, female gender, older age, and diabetes ${ }^{9}$.

The symptoms associated with the bladder and kidney infections are contrasting. Painful and frequent urination in case of cystitis as a result of bladder infection whereas high fever and flank pain in case of kidney infection are the common phenomena ${ }^{10}$.

The infection encompasses a diverse group of clinical syndromes and diseases that differ in epidemiology, etiology, and location severity of the condition ${ }^{11}$. In addition to the above factors, it also varies in symptoms, frequency of recurrence, extent of damage caused, and presence of complicating factors $^{12}$. The occurrence of bladder infection is usually followed by kidney infection, and results in blood-borne infection and in severe circumstances can lead to severe consequences including death. Therefore, UTI is capable of claiming lives under severe circumstances and proper treatment results in quick recovery from the contagion ${ }^{13}$.

In the presence of risk factors such as female sex, diabetes, obstructive uropathy, previous instrumentation, and chronic kidney disease (CKD), the treatment becomes even more challenging. Various studies done worldwide have shown changing pattern in etiology of UTIs ${ }^{3}$. The present trends of the uropathogens and their susceptibility to various antibiotics are essential to formulate guidelines for the empirical treatment of UTIs while awaiting the culture sensitivity ${ }^{12}$.

The major pathogens causing UTI are E. coli and pseudomonas sp, Proteus sp, klebsiella $s p \mathrm{etc}^{6}$. Increasing antibiotic resistance among urinary pathogens, especially E. coli, to commonly prescribed drugs like Cotrimoxazole has become a global reality?

Hence, the present study was an attempt to evaluate the current clinical and bacteriological profile of UTI patients in our hospital.

\section{Methods:}

This 6-month cross-sectional study was undertaken in the Department of Medicine, Sylhet MAG Osmani Medical College, Sylhet from January 2019 to June
2019 by convenient sampling. Total of 100 patients admitted Medicine indoor Department with symptoms (Urgency, frequency, dysuria, lower abdominal pain, loin pain, fever, vomiting, incontinence, confusional state) and signs (Increased temperature, loin and/or pelvic tenderness tenderness) of UTI confirmed by pertinent investigations $(\mathrm{CBC}$, Urine $\mathrm{R} / \mathrm{E}$ and $\mathrm{C} / \mathrm{S}$, USG of KUB in necessary cases, $\mathrm{S}$ Creatinine, RBS) including urinary culture either positive or negative were selected for the study. Patients aged $<13$ years were excluded from the study.

UTI involving Kidney and ureter is taken as upper UTI, whereas involving urinary bladder and urethra is taken as lower UTI. When the infection occurs in otherwise healthy and has no structural or neurological urinary tract abnormalities, it is an uncomplicated UTI. Complicated UTIs are defined as UTIs associated with factors that compromise the urinary tract or host defense, including urinary obstruction, urinary retention caused by neurological disease, immunosuppression, renal failure, renal transplantation, pregnancy, and the presence of foreign bodies such as calculi, indwelling catheters, or other drainage devices. Reinfection in urinary tract with any organism after an interval is taken as recurrent UTI. Bladder outflow obstruction, anatomical abnormality, neurological problems, foreign body, loss of host defense is taken as risk factors of UTI.

Detailed history was taken from patient and patient attendants regarding clinical presentation (including diagnosis, complication, risk factor and recurrence) of UTI.

Data were processed manually and analyzed with the help of SPSS version 22. Quantitative data were expressed as mean and standard deviation, qualitative data were expressed as frequency and percentage.

\section{Results:}

Among 100 patients of UTI, maximum were females $(67 \%)$ and the male to female ratio was $0.49: 1$. The most common age group was $46-60$ years (34\%). The mean age was $54.19 \pm 3.94$ years . The median age was 55 years and ranged between 17 to 100 years. Most of the patients completed primary education $(52 \%) .21 \%$ did not receive any institutional education. Most (54\%) of the patients belong to income range of 10,000 to 20,000 taka per month. (Table 1) 
Table 1

Demographic profile of study patients $(n=100)$

\begin{tabular}{lccc} 
Traits & & Frequency & Percentage \\
\hline Age & & & \\
& Mean & 54.19 & \\
& Minimum & 17 & \\
Maximum & 100 & 10 \\
$15-30$ & 10 & 23 \\
$31-45$ & 23 & 34 \\
$46-60$ & 34 & 24 \\
$61-75$ & 24 & 8 \\
$76-90$ & 8 & 1 \\
$91-105$ & 1 &
\end{tabular}

Gender

$\begin{array}{lll}\text { Male } & 33 & 33\end{array}$

Educational status

$\begin{array}{ccc}\text { None } & 21 & 21 \\ \text { Primary } & 52 & 52 \\ \text { Secondary } & 24 & 24 \\ \text { Tertiary } & 3 & 3\end{array}$

Socioeconomic status(Income range -Taka/month)

$\begin{array}{ccc}<10,000 & 32 & 32 \\ 0,000-20,000 & 54 & 54 \\ >20,000 & 14 & 14\end{array}$

Marrital status

$\begin{array}{ccc}\text { Married } & 95 & 95 \\ \text { Unmarried } & 5 & 5\end{array}$

Most of the patients had fever (55\%), followed by loin pain (37\%), burning and increased frequency of micturition (32\%), vomiting (28\%), urgency of urine (23\%), delirium (15\%) incontinence 18(\%). (Figure 1)

Figure 1: Symptoms of UTI

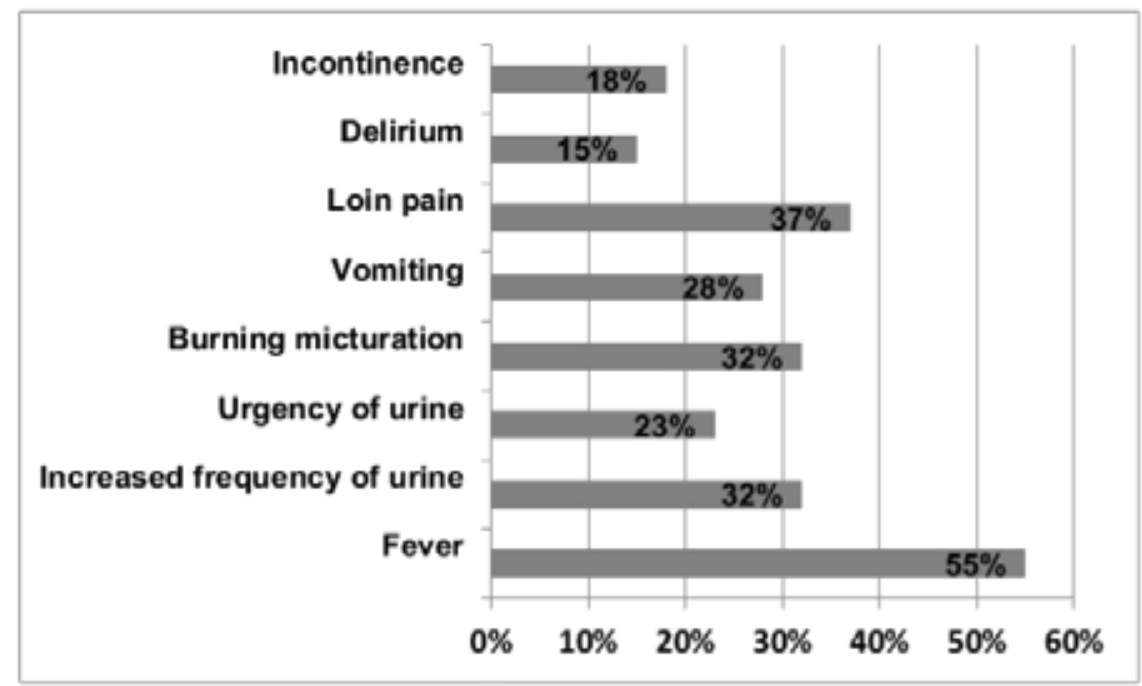


Majority (68\%) of the patients had upper UTI while lower UTI constitutes $32 \%$. $66 \%$ of the patients had complicated UTI, while $34 \%$ have uncomplicated UTI. 18\% of the patients had recurrent UTI. (Table 2)

Table 2

\begin{tabular}{lcc}
\multicolumn{3}{c}{ Pattern of UTI in study patients } \\
\hline Diagnosis & Frequency & Percentage \\
Upper UTI & 68 & 68 \\
Lower UTI & 32 & 32 \\
Complication Status & & \\
Complicated & 66 & 66 \\
Uncomplicated & 34 & 34 \\
Recurrence & & \\
Recurrent & 18 & 18 \\
Not recurrent & 82 & 82 \\
\hline
\end{tabular}

The most common risk factor was loss of host defense 38\% (diabetes mellitus/ use of immunosuppressive drugs) followed foreign body (17\%) like urethral catheter or stone anywhere in urinary pathway, $9 \%$ have bladder outflow obstruction like BEP or urethral stricture, 4\% have neurological problem like Stroke, and $4 \%$ have anatomical abnormality like uterine prolapse. (Figure 2)

\section{Figure 2: Risk factors of UTI patients}

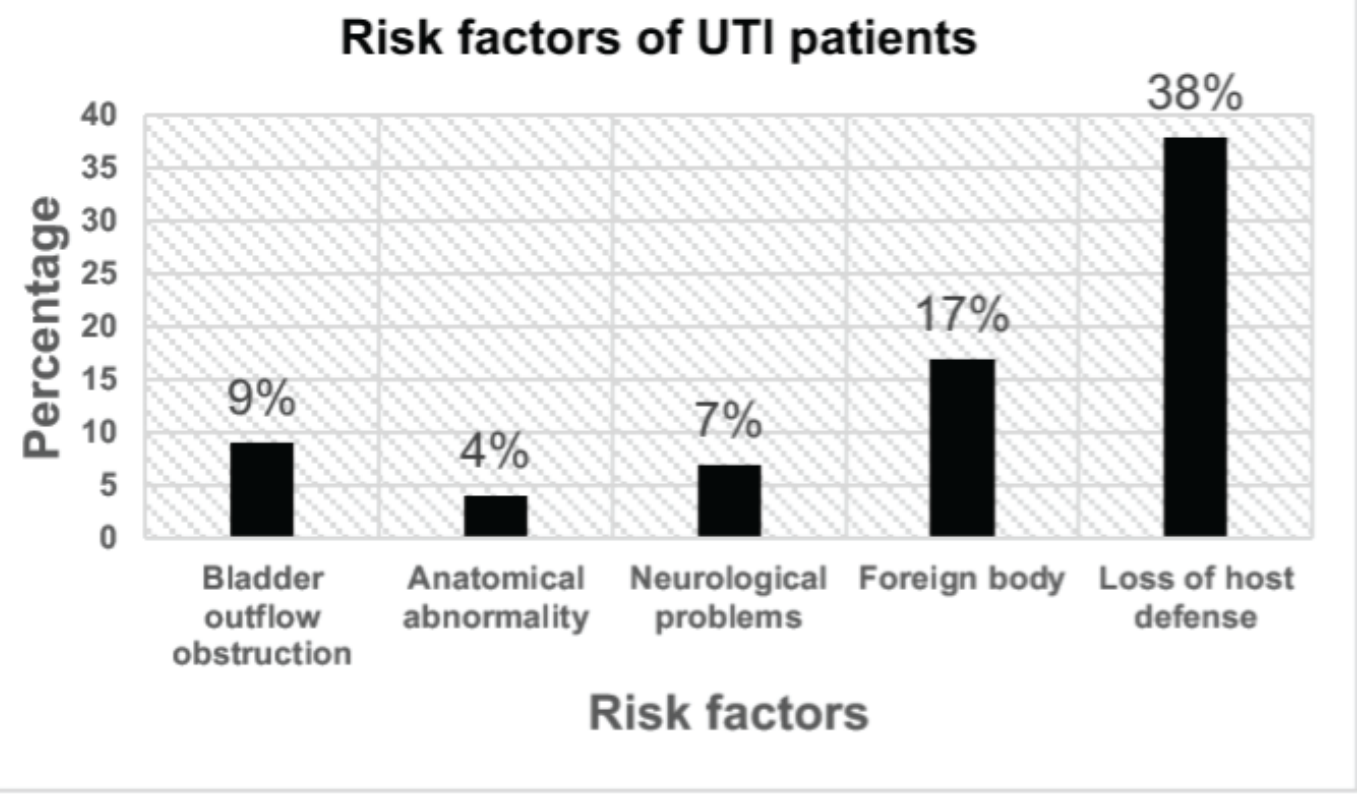


Table 3

\begin{tabular}{lcc} 
& \multicolumn{2}{c}{ Risk factors of UTI among study patients } \\
& $(\mathrm{n}=\mathbf{1 0 0})$ & \\
Traits & Frequency & Percentage \\
\hline Present & 60 & 60 \\
Absent & 40 & 40 \\
\hline
\end{tabular}

Out of 100 urine samples 60 were positive for pathogenic organisms. Escherichia coli was isolated in $41(68.3 \%)$ of the positive samples. This was followed by Klebsiella sp $13(21.6 \%)$, Pseudomonas sp $3(5 \%)$ Proteus sp 2 (3.3\%) Staph. Aureus 1 (1.66\%). (Table 4)

\section{Table 4}

\begin{tabular}{|c|c|c|}
\hline \multicolumn{3}{|c|}{ Microbiological pattern in study patients $(n=100)$} \\
\hline Traits & Frequency & Percentage \\
\hline \multicolumn{3}{|l|}{ Organism } \\
\hline Present & 60 & 60 \\
\hline Absent & 39 & 39 \\
\hline \multicolumn{3}{|l|}{ Gram Stain } \\
\hline Gram + ve & 1 & 1.7 \\
\hline Gram -ve & 59 & 98.3 \\
\hline \multicolumn{3}{|l|}{ Individual Bacteria } \\
\hline E Coli & 41 & 68.3 \\
\hline Klebsiella & 13 & 21.6 \\
\hline Pseudomonas & 3 & 5 \\
\hline Proteus & 2 & 3.3 \\
\hline Staph aureus & 1 & 1.6 \\
\hline
\end{tabular}


As a whole all organisms are mostly sensitive to Nitrofurantoin (86.2\%), Meropenem (93.1\%), Amikacin (77.2\%), and Gentamycin (64.9\%) and mostly resistant to Cefixime (83.3\%), Cefuroxime (81.4\%), and Ceftriaxone (66.9\%). (Figure 3)

\section{Figure 3: Antibiotic sensitivity of UTI patients}

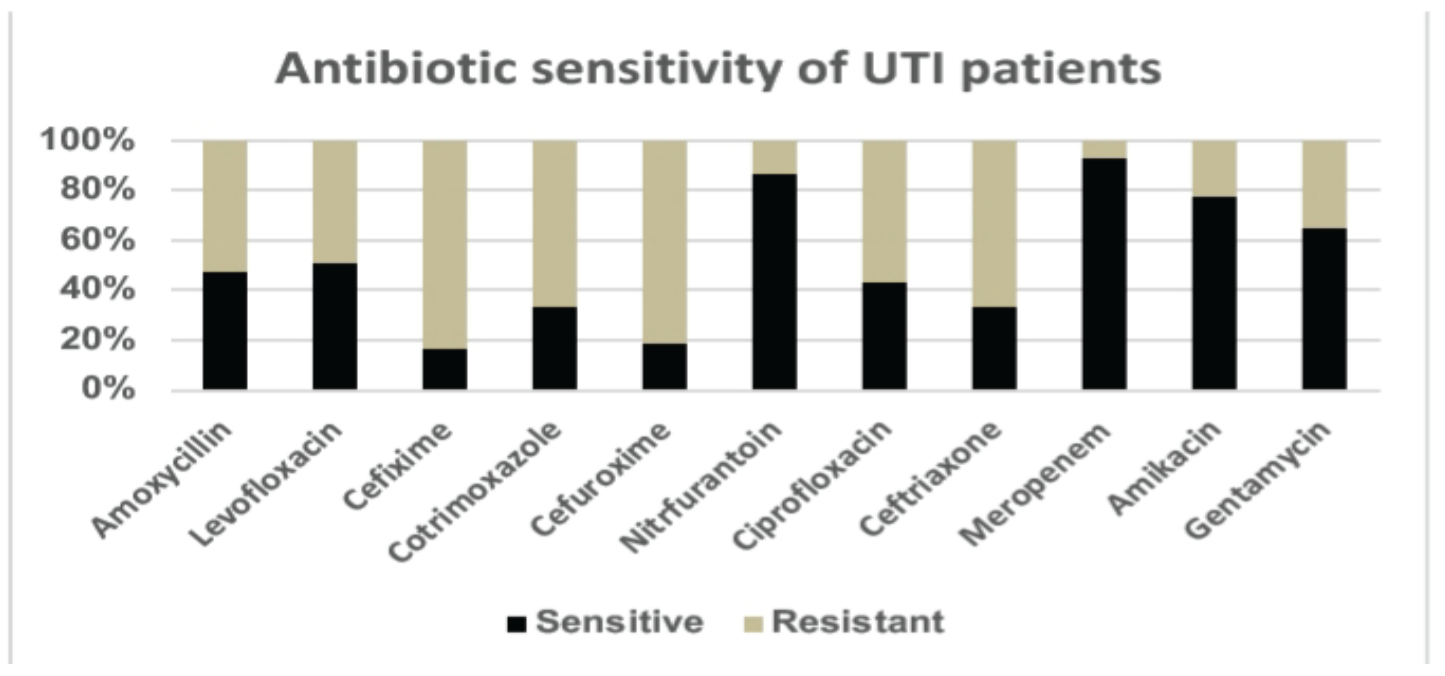

\section{Discussion:}

UTI is a common clinical problem in both the community and health care associated settings. Epidemiologically urinary tract infections account for seven million office visits and one million emergency department visits, resulting in 100,000 hospitalizations yearly, making them the most common bacterial infections in outpatient and emergency department setting. Financially, the estimated annual cost of UTI is significant, at approximately $\$ 1.6$ billion ${ }^{14}$.

In the present study, $67 \%$ of the patients were females and $33 \%$ of the patients were females with male female ratio of 0.49: 1 . Similar finding had been observed by another study by Kibret at el in Ethiopia which reported UTIs in $66 \%$ of the females and $34 \%$ of males ${ }^{15}$. The reason behind this high prevalence of UTI in females is due to proximity of the urethral meatus to the anus, shorter and wider urethra, sexual intercourse, incontinence, and less acidic $\mathrm{pH}$ of vaginal surface and poor hygienic conditions ${ }^{11-13}$.

The incidence of UTI increases with age ${ }^{16}$. In the present study, age ranged between 17 and 100 years. The most common age group was 46-60 years comprised of $34 \%$ of the patients and the mean age was $54.19( \pm 3.94 \mathrm{SD})$ years. A study from Vadodara, India showed maximum UTI patients in the age group of 50 to $69(41.25 \%)^{17}$.

UTI usually develops in the lower urinary tract (urethra and bladder), and if not properly treated, they ascend to the upper urinary tract (ureters and kidneys)and cause severe damaged to the kidneys ${ }^{16}$. In the present study, $66 \%$ of the patients had complicated type of UTI ( Remaining 6 UTI patients had been labeled as complicated UTI upon their pregnancy as because pregnancy with UTI is complicated. Pregnancy was not encountered as risk

factor for UTI in Data collection tool but history of pregnancy is documented in data). while $34 \%$ of the patients had uncomplicated UTI. These findings were consistent with a study by a Stefaniuk E et al. in Poland reported $37.8 \%$ of patients with uncomplicated UTI and $62.2 \%$ had a complicated infection ${ }^{18}$.

In the present study, the most common clinical presentation was fever noted in 55\%of the patients followed by loin pain which was present in $37 \%$ of the patients. The other presentations were increased frequency of urine and burning during micturition 
$32 \%$, vomiting $28 \%$, urgency of urine $23 \%$, incontinence $18 \%$, and delirium $15 \%$. A study from north Indian tertiary care center reported that most of the patients with symptomatic UTI complained of mild fever, increased frequency, and burning during micturition along with urgency ${ }^{11}$, while another study by Eshwarappa $\mathrm{M}$ et al. demonstrated fever and dysuria being the most common clinical presentation $^{19}$. Our study only included admitted patients which may explain the dominance of fever in the clinical presentation.

$60 \%$ of the patients have at least one risk factors, while $40 \%$ having no risk factors to develop UTI. The most common risk factor was loss of host defense $38 \%$ (diabetes mellitus/ use of immunosuppressive drugs) followed foreign body $(17 \%)$ like urethral catheter or stone anywhere in urinary pathway, $9 \%$ have bladder outflow obstruction like BEP or urethral stricture, $4 \%$ have neurological problem like Stroke, and $4 \%$ have anatomical abnormality like uterine prolapse. Similar study from South India reported that diabetes was the most common factor associated with complicated UTI which is consistent with the present study ${ }^{19}$. Nicolle LE et al. also demonstrated that the risk of developing UTI in diabetic patients is higher and urinary tracts the most common site for infection ${ }^{20}$.

Raval $\mathrm{R}$ et al. in his bacteriological study revealed the involvement of gram negative enteric organisms as commonly causing urinary tract infections, such as E. coli, the Klebsiella species, and the Proteus species. ${ }^{17}$.Findings in our study also coincide with the previous studies, gram negative bacilli was more common and Escherichia coli constituted the largest group with a prevalence of $68.3 \%$, followed by Klebsiellasp $21.6 \%$,Pseudomonas sp5\%, Proteus sp3.3\% and Staph Aureus sp 1.6\%.Similar finding is also reported in a recent study in Dhaka city of

Bangladesh where E coli was most frequent (69\%). ${ }^{21}$ Other investigators also reported higher association of E. coli ( $66.67 \%$ and $77.8 \%$ cases respectively) in UTI patients ${ }^{19,20}$.

Overall antimicrobial sensitivity and resistance of isolated uropathogens in this study showed relatively high resistance to Amoxicillin (52\%), Cotrimoxazole (66.90\%) Cefixime (83.30\%), Cefuroxime $(81.40 \%)$ and Ceftriaxone $(68.90 \%)$ which correlates with a previous study done by Haque et al in Bangladesh. ${ }^{22}$
Meropenem 93.1\%, Nitrofurantoin $86.20 \%$, Amikacin $77.20 \%$, and Gentamycin $64.90 \%$ were found to be sensitive to identified uropathogens. These findings are quite consistent to the findings of another study done in King Fahad Hospital Saudi Arabia $^{23}$.

Limitations of our study were small sample size, inclusion of only admitted patients which is not representative of total community. As we enrolled the patients of indoor setting of a Govt. Hospital, so poor educational status as well as low socioeconomic status were in background information.

\section{Conclusion:}

Based on the findings of this study, it may be concluded that, the most of the UTI patients present with fever, Loin pain, burning micturition and increased frequency of micturition. Vomiting, urgency of micturition, incontinence and delirium are less common as clinical presentation. Diabetes mellitus is the most important risk factor of UTI. Most frequent isolated bacteria was E-coli.

Acknowledgement: UTI patients of Sylhet MAG Osmani Medical College Hospital

\section{References:}

1. Prakash D, Saxena RS. Distribution and antimicrobial susceptibility pattern of bacterial pathogens causing urinary tract infection in urban community of meerut city, India. ISRN Microbiol. 2013 Oct 29;2013:749629. doi: 10.1155/2013/749629. PMID: 24288649; PMCID: PMC3830820. https://doi.org/ $10.1155 / 2013 / 749629$, PMid:24288649 PMCid:PMC3830820

2. Stamm WE, Norrby SR. Urinary tract infections: Disease panorama and challenges. J Infect Dis 2001;183 Suppl 1:S1-4. https://doi.org/10.1086/ 318850, PMid:11171002

3. Flores-Mireles AL, Walker JN, Caparon M, Hultgren SJ. Urinary tract infections: Epidemiology, mechanisms

of infection and treatment options. Nat Rev Microbiol 2015;13:269-84. https://doi.org/10.1038/nrmicro3432 PMid:25853778 PMCid:PMC4457377

4. Hamida K, Fahmida M, Shafiullah A. Z. M., Farhana M. Prevalence and comparative likelihood of urinary tract infection among female out patients in BSMMU. Bangladesh J. Zool. 2012 40(2): 231-39. https://doi.org/10.3329/bjz.v40i2.14317 
5. Hooton TM. Clinical practice. Uncomplicated urinary tract infection. N Engl J Med 2012;366:1028-37. https://doi.org/10.1056/NEJMcp1104429 PMid:22417256

6. Lichtenberger P, Hooton TM. Complicated urinary tract infections. Curr Infect Dis Rep 2008;10:499-504. https://doi.org/10.1007/s 1 1908-008-0081-0 PMid:18945392

7. Levison ME, Kaye D. Treatment of complicated urinary tract infections with an emphasis on drug resistant gram negative uropathogens. Curr Infect Dis Rep 2013;15:109-15. https://doi.org/10.1007/s11908013-0315-7, PMid:23378123

8. Lo E, Nicolle LE, Coffin SE, Gould C, Maragakis LL, Meddings $\mathrm{J}$, et al. Strategies to prevent catheter associated urinary tract infections in acute care hospitals: 2014 update. Infect Control Hosp Epidemiol 2014;35:464-79. https://doi.org/10.1086/ 675718, PMid:24709715

9. Chenoweth CE, Gould CV, Saint S. Diagnosis, management, and prevention of catheter associated urinary tract infections. Infect Dis Clin North Am 2014;28:105-19. https://doi.org/10.1016/j.idc.2013.09.002 PMid:24484578

10. Vasudevan R. Urinary tract infection: An overview of the infection and the associated risk factors. Microbiol Exp 2014;1:1-15. https://doi.org/10.15406/ jmen. 2014.01.00008

11. Khan R, Saif Q, Fatima K, Meher R, Shahzad HF, Anwar KS. Clinical and bacteriological profile of UTI patients attending a North Indian tertiary care center. J Integr Nephrol Androl2015;2:29-34.https://doi.org/ 10.4103/2225-1243.150009

12. Ochei J, Kolhatkar A. Diagnosis of infection by specific anatomic sites/antimicrobial susceptibility tests. In: Medical Laboratory Science Theory and Practice Reprint. 6th ed. New Delhi, India: McGraw-Hill; 2007. p. 615-43,788-98.

13. Ghadage DP, Muley VA, Sharma J, Bhore AV. Bacteriological profile and antibiogram of urinary tract infections at a tertiary care hospital. Natl J Lab Med 2016;5:MO20-24.

14. Aiyegoro OA, Igbinosa OO, Ogunmwonyi IN, Odjadjaro E, Igbinosa OE, Okoh AI. Incidence of urinary tract infections (UTI) among children and adolescents in Ile-Ife, Nigeria. Afr J Microbiol Res 2007;1:13-9.
15. Kibret, Mulugeta, and Bayeh Abera. "Prevalence and antibiogram of bacterial isolates from urinary tract infections at Dessie Health Research Laboratory, Ethiopia." Asian Pacific journal of tropical biomedicine vol. 4,2 (2014): 164-8. doi:10.1016/ S2221-1691(14)60226-4, https://doi.org/10.1016/ S2221-1691(14)60226-4

16. John AS, Mboto CI, Agbo B. A review on the prevalence and predisposing factors responsible for urinary tract infection among adults. Eur J Exp Biol 2016;6:7-11.

17. Raval R, Verma RJ, Kareliya H. Clino-pathological features of urinary tract infection in rural India. Adv Infect Dis 2015;5:132-9. https://doi.org/10.4236/ aid.2015.54016

18. Stefaniuk E, Suchocka U, Bosacka K, Hryniewicz W. Etiology and antibiotic susceptibility of bacterial pathogens responsible for community-acquired urinary tract infections in Poland. Eur $\mathrm{J}$ Clin Microbiol Infect Dis 2016;35:1363-9. https://doi.org/ 10.1007/s 10096-016-2673-1,PMid:27189078 PMCid:PMC4947106

19. Eshwarappa M, Dosegowda R, Aprameya IV, Khan MW, Kumar PS, Kempegowda P, et al. Clinico-microbiological profile of urinary tract infection in South India. Indian $\mathrm{J}$ Nephrol 2011;21:30-6. https://doi.org/10.4103/0971-4065. 75226, PMid:21655167 PMCid:PMC3109780

20. Nicolle LE. Asymptomatic bacteriuria in diabetic women. DiabetesCare2000;23:722-3. https://doi.org/ 10.2337/diacare.23.6.722, PMid:10840984

21. Rahman SR, Ahmed MF, Begum A. Occurrence of urinary tract infection in adolescent and adult women of shanty town in Dhaka City, Bangladesh. Ethiop J Health Sci. 2014 Apr;24(2):145-52. doi: 10.4314/ ejhs.v24i2.7. PMID: 24795516; PMCID: PMC4006209. https://doi.org/10.4314/ejhs.v24i2.7 PMid:24795516 PMCid:PMC4006209

22. Haque R, Akhtar ML, Salam MA Prevalance and susceptibility of uropathogens: A recent report from a teaching hospital in Bangladesh.BMC Research Notes 2015; 8:416. https://doi.org/10.1186/s13104-0151408-1, PMid:26342570 PMCid:PMC4560919

23. Al-Zahran AJ, Akhtar N. Susceptibility patterns of extended spectrum beta-lactamase (ESBL) -producing Escherichia coli and Klebsiella pneumonia isolated in a teaching hospital. Pak J Med Res 2005;44:64-7. 